
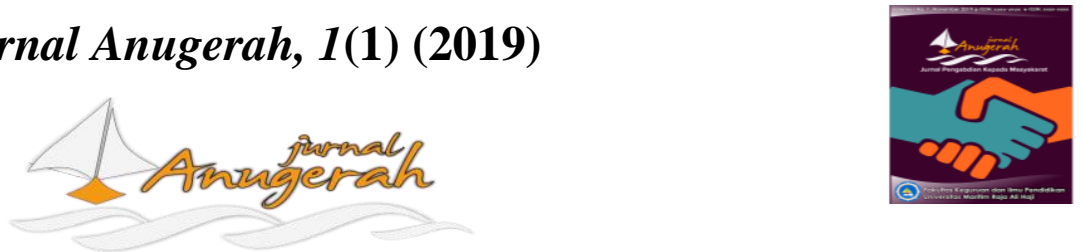

https://ojs.umrah.ac.id/index.php/anugerah

\title{
Pentingnya Stepping the 5 Stairs “ $A$ ” Teknik untuk Anak-anak Pesisir yang Belajar Grammar
}

\author{
Satria Agust ${ }^{1 *}$, Gatot Subroto ${ }^{2}$, Muhammad Candra ${ }^{3}$ \\ ${ }^{1,2,3}$ Uversitas Maritim Raja Ali Haji, Tanjungpinang, Kepulauan Riau 29124, Indonesia \\ *e-mail korespondensi: ${ }^{*}$ satria.agust@gmail.com, \\ Pengiriman: 24 Oktober 2019; Diterima: 21 November 2019; Publikasi: 28 November 2019
}

\begin{abstract}
Abstrak
Pengalaman belajar Bahasa Inggris khususnya Grammar harus dilakukan dengan cara yang menyenangkan dan sekaligus membuat pelajar bahasanya menguasai konsepnya dengan baik. Pentingnya penguasaan Grammar dengan baik memudahkan pelajar bahasa untuk mengunstruksi kalimat-kalimat Bahasa Inggris dari berbagai tensis. Anak-anak pesisir belum dibekali pemahaman yang baik tentang grammar dan tidak punya cukup waktu untuk belajar grammar di sekolah. Untuk menguasai Grammar tersebut, Stepping the 5 Stairs "A" teknik menawarkan pembelajaran grammar yang menyenangkan. Sudah ada banyak teknik yang ditawarkan. Akan tetapi teknik-teknik yang ada belum mengakomodir karakteristik cara belajar pelajar bahasa tersebut yang berasal dari daerah tertentu. Pendekatan deskriptif merupakan metode pelaksanaan pengabdian kepada masyarakat (PkM) ini. Tim PkM melakukan survey lokasi dan melakukan wawancara kepada beberapa perwakilan warga dan orang tua anak-anak pesisir tersebut. Lokasi pelaksanaan kegitan PkM adalah di Kelurahan Senggarang yang merupakan salah satu tempat kunjungan wisata bagi turis-turis asing. Hasil kegiatan PkM ini adalah: (1) Adanya peningkatan pengetahuan dan pemahaman anak-anak pesisir tentang pembelajaran Grammar dengan menggunakan teknik Stepping the 5 Stairs "A", (2) adanya motivasi anak-anak pesisir untuk tetap belajar Grammar, dan (3) Adanya permintaan dari anak-anak pesisir, para orang tua, RT, RW, dan Karang Taruna Senggarang kepada tim PkM untuk tetap meneruskan kegiatan serupa kedepannya.
\end{abstract}

Kata kunci:stepping the 5 Stairs "A"; grammar; anak-anak pesisir

\begin{abstract}
The English learning experience especially Grammar should be done in a fun way and make the language learners master the concept well. The importance of mastering Grammar well facilitates language learners to construct English sentences from various tenses. Coastal language learners have not been given a good grammar understanding and do not have enough time to learn grammar in schools. To master Grammar, Stepping the 5 Stairs "A" technique offers fun grammar learning. There are already many techniques offered. However, the existing techniques do not accommodate the characteristics of the language learning methods of those from certain regions. Descriptive approach is a method of implementing community service. The team conducted a site survey and interviews with several residents' representatives and coastal learners' parents. The community service location is in Senggarang Village where foriegn touristspay a visit. The results of the community service are: (1) An increase in the knowledge and understanding of coastal learners about Grammar learning by using the Stepping the 5 Stairs "A" technique, (2) Coastal learners'the motivation to continue learning Grammar, and (3) There are requests from coastal learners, parents, RT, RW, and Karang Taruna Senggarang to the team to continue similar activities going forward.
\end{abstract}

Keywords:stepping the 5 Stairs "A"; grammar; coastal learners

\section{Pendahuluan}

Grammar dalam bahasa Inggris menjadi momok bagi para pelajar bahasa tersebut. Hal ini bukan dilakukan tanpa alasan. Mengingat sulitnya mengkonstruksi kalimat bahasa Inggris yang benar sesuai konteks dan tensisnya menjadi pilar utama alasan para pelajar tersebut. Pelaksana pengabdian ini juga pernah 
menyebarkan angket terkait mata kuliah yang paling tidak disenangi dalam belajar bahasa Inggris. Grammar menjadi juaranya. Setelah didalami, alasan mereka yang tidak suka bahasa Inggris berasal dari faktor internal yakni memang dari diri pelajar itu sendiri. Mereka menganggap sesuatu yang pasti itu sangat membingungkan. Pada faktor eksternal, mahasiswa mempunyai pengalaman yang kurang baik dalam belajar Bahasa Inggris. Ada yang bilang karena bahasanya memang sulit. Ada juga yang mengatakan metode gurunya yang membuat grammar tersebut menjadi semakin sulit. Ada juga yang memberi alasan pura-pura senang atau ikut-ikutan teman yang lain senang. Ketika berada di kelas, sebagian siswa mengatakan bahwa grammar menyebabkan mereka tidak nyaman dan terkadang bahkan menjadi teror (Al-Mekhlafi \& Nagaratnam, 2011).

Sudah barang tentu, situasi serupa juga terjadi di lingkungan pelajar pesisir. Bukan perkara yang mudah untuk mengubah mindset mereka yang sudah menggurita. Sejauh ini, para pakar bahasa telah berusaha untuk menawarkan model, teknik, strategi, atau pendekatan yang baru untuk menyelesaikan permasalahan di atas dalam konteks baik bahasa Inggris sebagai bahasa asing mau pun bahasa Inggris sebagai bahasa kedua. Pada dekade terakhir telah menyaksikan peminatan yang dihidupkan kembali dalam pengajaran tata bahasa baik dalam konteks Inggris sebagai bahasa asing mau pun Inggris sebagai bahasa kedua sebagaimana telah dibuktikan oleh banyak publikasi terkait permasalahan ini, termasuk lah publikasipublikasi yang menunjukkan penting dan manfaat pengajaran tata bahasa pada pemerolehan bahasa para siswa(Ellis, 2005; Ellis, 2001; Ellis, 2002; Philp, 2003; Yuan \& Ellis, 2003) dan publikasi-publikasi yang mendukung teori dan pendekatan baru untuk pengajaran tata bahasa (Conrad, 2000; Ellis, 1995; Hahn, 2000; Hinkel \& Fotos, 2002; Hughes \& McCarthy, 1998; Liu \& Master, 2003).

Namun demikian, sangat disayangkan bahwa tawaran mereka belum bisa menuntaskan permasalahan di atas. Dari model pembelajaran yang tradisional hingga pembelajaran grammar berbasis komputer, seperti Computer-Assisted Langguage Learning (CALL) telah memberikan kontribusinya. Meskipun demikian, CALL belum tentu bisa diaplikasikan pada semua jenis lingkungan para pelajar. Keterbatasan sarana dan prasarana akan menjadi faktor penghambat utama untuk CALL tersebut. Walaupun Ragan, et al., (1993) mengatakan bahwa pemanfaatan multimedia bisa mengurangi waktu pembelajaran hingga 30\% dibandingkan dengan menggunakan model tradisional, bagi mereka yang tidak punya sarana dan prasarana pendukung, model tradisional tetap lah jauh lebih efektif dan menjadi favorit.

Kurikulum di Indonesia menetapkan peraturan yang berubah-rubah terkait mata pelajaran Bahasa Inggris di sekolah-sekolah. Kurun waktu sebelumnya, Bahasa Inggris dipelajari dari kelas satu sekolah dasar. Kemudian, kurikulum SD terkait pelajaran Bahasa Inggris tidak lagi menjadi pelajaran inti. Ironisnya, walaupun para siswa itu sudah mempelajari Bahasa Inggris hingga tingkat sekolah atas dan juga sudah dinyatakan lulus, tetap saja mereka tidak bisa berbahasa Inggris. Bahkan, beberapa diantaranya tidak mengerti Bahasa Inggrissama sekali. Di samping itu, ada juga yang bisa berbahasa Inggris secara komunikatif. Akan tetapi secara tatanan bahasanya masih belum benar. Walaupun para pelajar mempunyai kemampuan komunikasi yang baik hingga bisa digolongkan kedalam bahasa kedua (L2), tetap saja masih mengalami permasalahan terkait ketepatan berbahasa dan kesalahan struktur berbahasanya (Harley \& Swain, 1984; Lightbown, 1990).

Konsep Grammar biasanya membawa gagasan tentang bidang bahasa tertentu, terutama bagian dari ucapan ke dalam pikiran peserta didik ESL. Secara tradisional di kelas bahasa Inggris, pengajaran bahasa Inggris berarti mengajar beberapa bentuk kata dengan fokus pada bagian-bagian tata bahasa seperti kata kerja, kata benda, dan lain-lain. Pelajaran di sekolah jarang fokus pada kemampuan produksi siswa seperti berbicara atau menulis, tetapi mereka tertarik menguasai aturan tata bahasa. Pola pelajaran ini diubah dengan diperkenalkannya pendekatan komunikatif untuk mengajar bahasa Inggris dengan tetap mempertimbangkan aspek-aspek kebahasaan yang lain seperti keterampilan membaca, menulis, tata bahasa, dan kosa kata (Navaz \& Sama, 2017). 
Pengajaran grammar itu sendiri bisa dilakukan secara tradisional dan juga bisa dilakukan dengan sistim pembelajaran terpadu dengan mengaitkan keahlian bahasa yang lain. Dengan metode pembelajaran seperti ini, metode pembelajaran grammar tidak menjadi fokus utama. Akan tetapi, para pelajar bahasa bisa mendapatkan konteks yang jelas bagai mana tensis tertentu digunakan dalam suatu konteks. Kelebihan dengan sistim pembelajaran terpadu ini terletak pada aspek komunikasi yang baik bagi para pelajar bahasa. Sebaliknya, kemampuan mereka berkomunikasi yang lancar tidak didukung dengan kualitas berbahasa yang baik pula. Aspek-aspek tata bahasa yang disajikan dengan cara dekontekstual tradisional dapat diingat dalam konteks yang sama, seperti berfokus pada nilai tes tata bahasa, tetapi sulit untuk mengambilnya dalam konteks komunikatif (Lightbown, 2008).

Sebelumnya, bahasa Inggris telah menjadi mata pelajaran wajib untuk anak-anak didik di Indonesia dan bahkan di beberapa negara bahasa Ingris diajarkan kepada anak-anak usia dini yang terkenal dengan istilah Teaching English to Young Learners. Di Indonesia, pelajaran bahasa Inggris telah dikenalkan pada level Taman Kanak-Kanak agar mereka mampu memperolehnya dengan baik. Akan tetapi banyak sekali siswa-siswa yang sudah lulus SMA tidak bisa berkomunikasi dengan menggunakan bahasa Inggris. Pertanyaannya adalah kenapa hal itu bisa terjadi setelah kurang lebih 12 tahun belajar bahasa Inggris namun tidak bisa berbahasa Inggris?

Untuk menjawab pertanyaan di atas perlu dilakukan telaah secara komprehensif. Kemungkinankemungkinan yang bisa dianalisa adalah (1) kesalahan metode/strategi/teknik/pendekatan/media belajar yang digunakan oleh guru; (2) tidak tercapainya kompetensi inti dalam bahasa Inggris yang sudah ditetapkan dalam kurikulum sekolah-sekolah; (3) terlalu banyak menggunakan buku-buku teks bahasa Inggris untuk memperoleh bahasa Inggris; (4) adanya masalah-masalah yang dibuat oleh guru-guru bahasa Inggris; (5) adanya masalah-masalah yang dibuat oleh siswa-siswa pada saat belajar bahasa Inggris; (6) adanya masalahmasalah ruangan kelas ketika belajar bahasa Inggris; (7) fasilitas-fasilitas yang kurang memadai untuk memperoleh bahasa Inggris; atau (8) siswa-siswa mengalami trauma dalam belajar bahasa inggris. Mungkin, ada banyak lagi potensi-potensi yang menyebabkan fenomena ini terjadi pada para pelajar bahasa Inggris.

Realita yang tampak di depan mata adalah status bahasa Inggris di Indonesia masih sebagai bahasa asing bukan sebagai bahasa kedua. Itulah sebabnya bahasa Inggris masih jarang terdengar digunakan dalam komunikasi sehari-hari dimanapun kita berada. Disamping itu, mindset yang tertanam di kepala siswa-siswa adalah bahwa bahasa Inggris hanya sekedar bagian dari mata pelajaran yang kurang menyenangkan. Apa lagi kalua mereka harus mempelajari grammar dimana menurut hasil penelitan para pakar bahasa, grammar merupakan aspek bahasa yang paling sulit untuk dipahami. Kalau para pelajar sudah mempunyai sugesti seperti ini, model pembelajaran apa pun tidak akan pernah berhasil untuk mengubahnya. Secara tidak langsung, pengajaran bahasa Inggris di bangku sekolah akan terhambat. Untuk itu, perubahan mindset dari hal yang negatif ke hal yang positif perlu dilakukan sejak dini. Salah satu caranya adalah dengan mengenalkan hal-hal yang baru kepada siswa-siswa dengan cara yang menyenangkan. Itu lah kenapa Stepping the 5 Strairs " $A$ " itu ditawarkan dengan tujuan agar bisa merubah pikiran negatif terhadap grammar. Stepping the 5 Stairs " $A$ " merupakan teknik pembelajaran grammaryang masih dalam tahap pengembangan oleh tim PkM yang telah melaksanakan pengabdian kepada masyarakat.

Dengan permasalahan yang telah dipaparkan sebelumnya, potensi untuk menyelesaikan masalahmasalah tersebut sangat memungkinkan. Stepping the 5 Stairs "A" adalah teknik pembelajaran grammar yang merupakan buah dari hasil desain pengembangan atau penelitian berbasis desain. Berdasarkan hasil penelitian, desain ini sangat praktis dan mampu meningkatkan nilai grammar mahasiswa dari hasil perbandingan nilai rata-rata grammar para siswa dari pelaksanaan pra dan pascaujian. Teknik ini masih akan terus dikembangkan untuk dicari efektivitasnya khususnya untuk diimplementasikan di sekolah-sekolah dan anak-anak pesisir khususnya. Tulisan ini menyajikan paparan tentang bagaimana stepping the 5 Stairs " $A$ " mampu membantu anak-anak pesisir mengkonstruksi kalimat-kalimat full verbsbahasa inggris dengan benar dan akurat dengan atmosfir pembelajaran yang lebih santai dan menyenangkan. 


\begin{abstract}
Metode
Metode pelaksanaan pengabdian kepada masyarakat $(\mathrm{PkM})$ ini adalah metode langsung (direct method) dan melalui kegiatan pendampingan(advokasi). Pada waktu pra kegiatan, tim PkM telah melakukan survey lokasi dan melakukan wawancara kepada beberapa perwakilan warga dan orang tua siswa sekolah terkait kebutuhan Bahasa Inggris untuk anak-anak mereka di Kelurahan Senggarang. Lokasi pelaksanaan kegitan PkM adalah di Kelurahan Senggarang yang mana daerah ini merupakan salah satu tempat kunjungan wisata bagi turis-turis asing. Waktu pelaksanaan PkM ini adalah 4 (empat) minggu dari bulan Juli sampai dengan Agustus 2019 dan untuk hasilnya telah dianalisa dengan menggunakan metode deskriptif. Untuk mengetahui sejauh mana pemahaman anak-anak pesisir mengenai materi yang telah diberikan, tim PkMmenyebarkan angket yang berisi 10 (sepuluh) butir pernyataan yang kemudian dianalisa secara deskriptif. Observasi dari pra hingga dalam pelaksanaan kegiatan juga menjadi metode dalam pengumpulan data.

Kegiatan PkM ini diawali dengan perkenalan Tim Pelaksana PkM yang melibatkan 4 (empat) mahasiswa ini kepada aparatur kelurahan setempat seperti Pak Rukun Warga (RW), Rukun Tetangga (RT), pereakilan beberapa orang tua anak-anak pesisir, serta anak-anak pesisir sebagai subyek dalam pelakasanaan PkM ini. Setelah sesi perkenalan selesai, Tim PkMmenggunakan metode pengajaran langsung (direct teaching method) dengan menggunakan teknik stepping the 5 Stairs "A". Tim PkM memulai pengajarandengan terlebih dahulu membagi anak-anak pesisir kedalam 4 (empat) kelompok untuk belajar Bahasa Grammar dengan menggunakan teknik Stepping the 5 Stairs "A" di dua lokasi yang berbeda, yakni di Mushola dan di Ruang PAUD. Keberhasilan PkM ini diukur dengan menggunakan beberapa indikator, diantaranya adalah: (1) 24 dari 25 anak-anak pesisir (96\%)berperan aktif dalam kegiatan PkM ini, (2) Waktu kegiatan PkM ini terlaksana 100\%, (3) Keinginan yang kuat dari anak-anak pesisir agar PkM ini bisa diteruskan, dan (4) 23 dari 25 peserta (92\%) mampu memahami dan mengimplementasikan teknik Stepping the 5 Stairs " $A$ " dalam belajar Grammar.
\end{abstract}

\title{
Hasil dan Pembahasan
}

Dari hasil pengamatan Tim PkM, peserta sangat tegang dalam mengikuti kegiatan PkM tersebut apalagi yang mereka pelajari adalah grammar bahasa Inggris. Pada saat mereka diwawancara, mereka mengakui kemampuan mereka dalam bahasa Inggris khususnya grammar masih sangat kurang. Temuan ini sejalan dengan hasil kegiatan PkM dengan judul "Pelatihan Bahasa Inggris Melalui Media Gambar dengan Direct Method (Metode Langsung)" yang mana pelaksana PkM menemukan bahwa Peserta PkM masih kurang dalam hal praktik bahasa Inggris dan pelatihan secara berkelanjutan dirasa perlu. Hanya sebagian peserta saja yang punya kemampuan untuk berkomunikasi bahasa Inggris dengan baik (Risnawaty, 2018). Kehadiran Tim PkM yang dilaksanakan selama 4 (empat) pertemuan tidak menawarkan suatu metode pembelajaran melainkan menawarkan suatu teknik pembelajaran Grammar yang menyenangkan, yakni Stepping the 5 Stairs " $A$ ". Teknik ini telah mampu mampu membuat suasana pembelajaran lebih santai, tidak menegangkan, dan menyenangkan. Teknik ini berfokus pada kontruksi kalimat-kalimat bahasa Inggris yang menggunakan full-verb dari berbagai tensis. Gambar 1 menunjukan atmosfir kegiatan PkM yang pesertanya yang merupakan anak-anak pesisir masih tampak tegang ketika dalam proses pembelajaran sebelum teknik Stepping the 5 Stairs " $A$ " diimplementasikan pada pertemuan pertama kegiatan. 


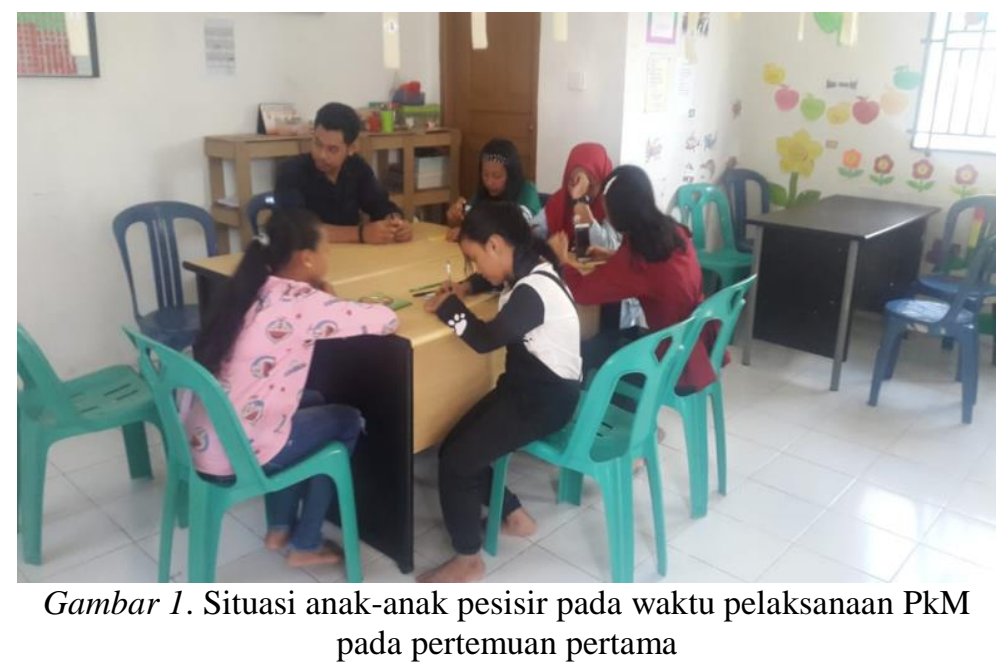

Berdasarkan hasil interview oleh Tim PkM mengapa mereka tegang dalam mengikuti kegiatan PkM untuk belajar Grammar, jawaban mereka adalah karena grammar itu sulit dipelajari dan mereka merasa tidak paham apa yang telah dipelajari di sekolah mereka. Hasil interview Pengabdian kepada Masyarakat ini sesuai dengan hasil interview PkM yang berjudul "Pelatihan Berbahasa Inggris dengan Drilling dan Repetition bagi Karang Taruna Desa Jedong” yang mana Tim pelaksana menyatakan bahwa sebelumnya peserta PkM mengakui bahwa bahasa Inggris itu sulit walaupun telah belajar secara maksimal di sekolah dan masih perlu mendapatkannya dari kegiatan belajar di luar pelajaran sekolah (Andy \& Muzammil, 2018). Pernyataan serupa juga disampaikan oleh Hasanah (2016) terkait hasil PkMnya bahwa menurut peserta PkM, keefektifan internet sebagai sarana pembelajaran grammar masih dirasa belum maksimal dan mereka menambahkan keterlibatan langsung untuk belajar grammar (seperti di kelas) lebih efektif dan meningkatkan pengetahuan mereka. Hasil PkM ini dijustifikasi oleh Agust (2017) bahwa dari 200 mahasiswa, 80 mahasiswa (40\%) menyatakan bahwa materi grammar membuat mereka tidak suka grammar dan 120 diantaranya (60\%) mengatakan bahwa mereka tidak suka grammar karena gurunya. Meskipun persentase yang lebih tinggi terdapat pada gurunya, ini bukan semata kesalahan guru tersebut. Penilaian negatif mahasiswa pada mata kuliah grammarsebagai penyebab utamanya. Penelitian saat ini di Tanjungpinang (Indonesia) melibatkan 82 mahasiswa Pendidikan Bahasa Inggris menunjukkan bahwa mereka menaruh minat mereka pada unsur-unsur bahasa dengan persentase yang berbeda pada pronunciation $64 \%$, vocabulary $25 \%$, dan grammar $11 \%$. Persentase tertinggi jatuh pada pronunciation. Mereka memang menyukai mata kuliah ini. Yang berada di bwahnya adalah vocabulary. Tampaknya belajar vocabulary itu menyenangkan. Yang paling bawah adalah grammar. Mereka tidak menunjukkan passion-nya pada mata kuliah ini. Dengan demikian, ini dapat diasumsikan mata kuliah grammar paling tidak disukai (Agust, 2019).

Pada pertemua kedua kegiatan, ketegangan sudah tidak tampak lagi di raut wajah para peserta PkM. Mereka sudah lebih relaks dalam belajar grammar. Ini karena kepercayaan diri mereka sudah lebih baik setelah mengerti cara mengkonstruksi kalimat-kalimat full verb bahasa Inggris dengan menggunakan Stepping the 5 Stairs “ $A$ ” dengan benar. Mereka juga paham setiap fungsi anak-anak tangga teknik tersebut. Justifikasi hasil PkM ini selaras dengan hasil PkM yang berjudul "Penggunaan Aplikasi Duolingo Dalam Meningkatkan Kamampuan Kosakata Bahasa Inggris Pada Tenaga Pengajar Bimbingan Belajar Omega Sains Institut" bahwa peserta pelatihan mengerti mekanisme kerja dan fungsi aplikasi Duolingo sebagai media pembelajaran bahasa Inggris digunakan sebagai alat bantu guru untuk mengajar bahasa Inggris di kelas (Widyastuti \& Kusumadewi, 2018). Ini menunjukan bahwa pemilihan dan penggunaan teknik atau metode yang tepat terhadap pelajaran grammar atau bahasa Inggris pada umumnya bisa sangat membantu anak-anak pesisir dalam belajar bahasa Inggris, khususnya grammar. 


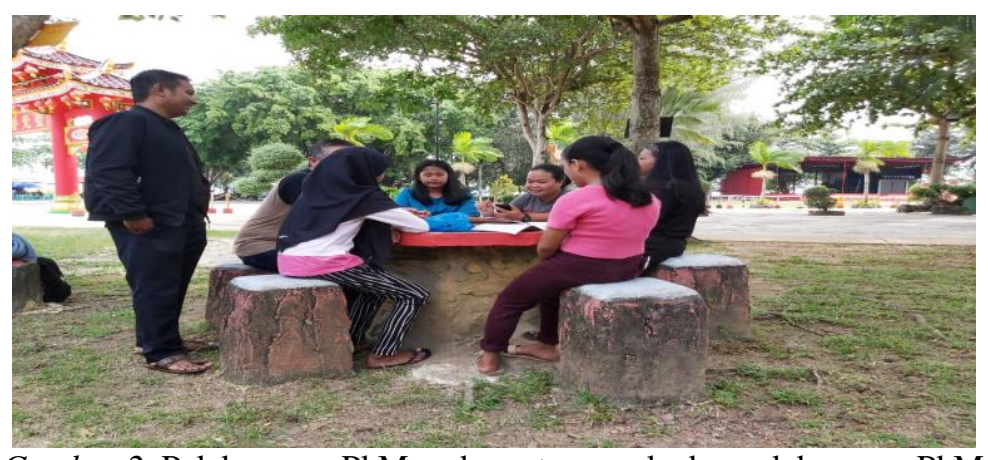

Gambar 2. Pelaksanaan PkM pada pertemuan kedua pelaksanaan PkM di Taman Vihara Senggarang

Pada pertemuan ketiga kegiatan, anak-anak pesisir sudah bisa belajar mandiri untuk mengkonstruksi kalimat bahasa Inggris full verb dengan benar dan akurat. Mereka pun semakin percaya diri dan semakin santai tenang dalam proses pembelajaran. Soft skill yang ditawarkan oleh teknik Stepping the 5 Stairs "A" muncul dalam diri anak-anak pesisir ketika mengimplementasikan teknik tersebut. Hasil PkM ini dikonfirmasi oleh hasil pengabdian sebelumnya bahwa kegiatan PkM ini sangat memuaskan karena peserta PkM berhasil untuk mengeksplor kemampuan bahasa Inggrisnya dengan lancar. Peserta terampil untuk membuat Self-study book. Hasil ini berimplikasi kepada kesuksesan pada Tim PkM dalam melaksanakan kegiatan ini (Setyowati \& Muthoharoh, 2018). Peran tim PkM sudah tidak 100\% lagi. Tim PkM hanya sebagai fasilitator dan monitor proses pembelajaran yang sedang berlangsung. Gambar 3 menunjukan proses pembelajaran grammar dengan teknik stepping the 5 Stairs " $A$ " di taman Vihara Senggarang. Hasilnya pun sangat memuaskan karena anak-anak pesisir tersebut sudah sangat mandiri dan mampu untuk mengkonstruksi kalimat-kalimat bahasa Inggris dengan benar dan akurat.

Pada pertemuan keempat, tim PkM menemukan bahwa keinginan yang kuat dari semua peserta PkM untuk kegiatan pembelajaran ini masih berkelanjutan. Repon anak-anak pesisir dari hasil angket yang disebarkan sangat positif terkait kegiatan PkM ini. Semua anak-anak pesisir (100\%) sangat setuju agar kegiatan serupa masih dilanjutkan. Keberlanjutan kegiatan PkM (Risnawaty, 2018; Andy \& Muzammil, 2018; Hasanah, 2016; Setyowati \& Muthoharoh, 2018; Widyastuti \& Kusumadewi, 2018) menjadi harapan semua peserta Pengandian kepada Masyarakat. Hasil PkM ini selaras dengan hasil PkM yang telah dilakukan oleh Andy \& Muzammil (2018). Mereka menyatakan bahwa pelaksanaan kegiatan pengabdian masyarakat dapat sambutan baik dan dan terlaksana sesuai dengan yang diharapkan walaupun ada hal teknis terkait penyesuaian jadwal kegiatan anggota karang taruna yang sudah punya agenda tujuhbelasan. Menurut peserta PkM, metode drilling dan repetition meningkatkan kemampuan bahasa Inggris mereka secara lisan dalam hal kosakata, tatabahasa, pengucapan, dan pelafalan.

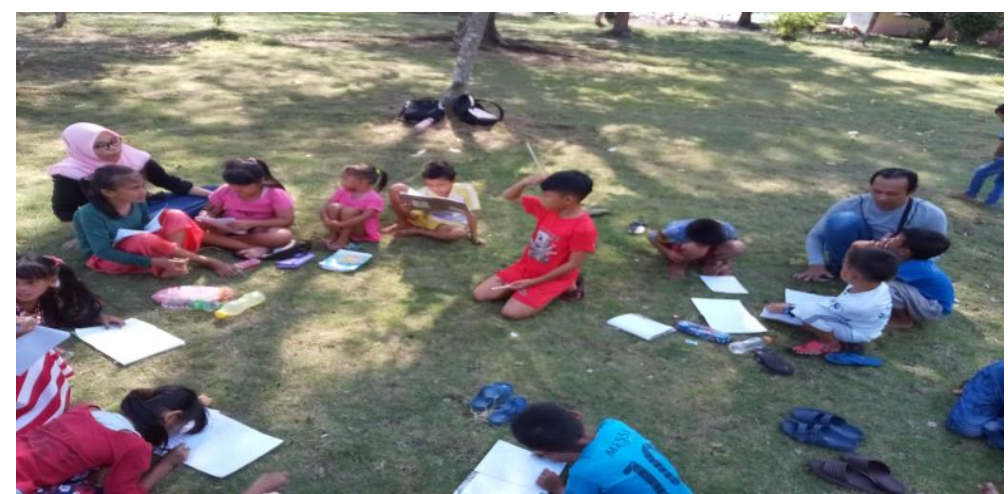

Gambar 3. Pelaksanaan PkM pada pertemuan ketiga pelaksanaan PkM di Taman Vihara Senggarang 
Gambar 4 menjelaskan suasana akhir pelaksanaan PkM. Mereka telah memiliki teknik baru untuk mengkonstruksi kalimat-kalimat bahasa Inggris full verbs dengan benar dan akurat. Materi grammar yang diberikan oleh tim PkM kepada mereka mampu dipahami dengan baik dengan menggunakan teknik stepping the 5 Stairs " $A$ ". Pernyataan ini didukung dari hasil angket yang diisi mereka. Seluruh peserta PkM sangat setuju bahwa materi grammar bisa dipahami dengan mudah yang diberikan oleh tim PkM.

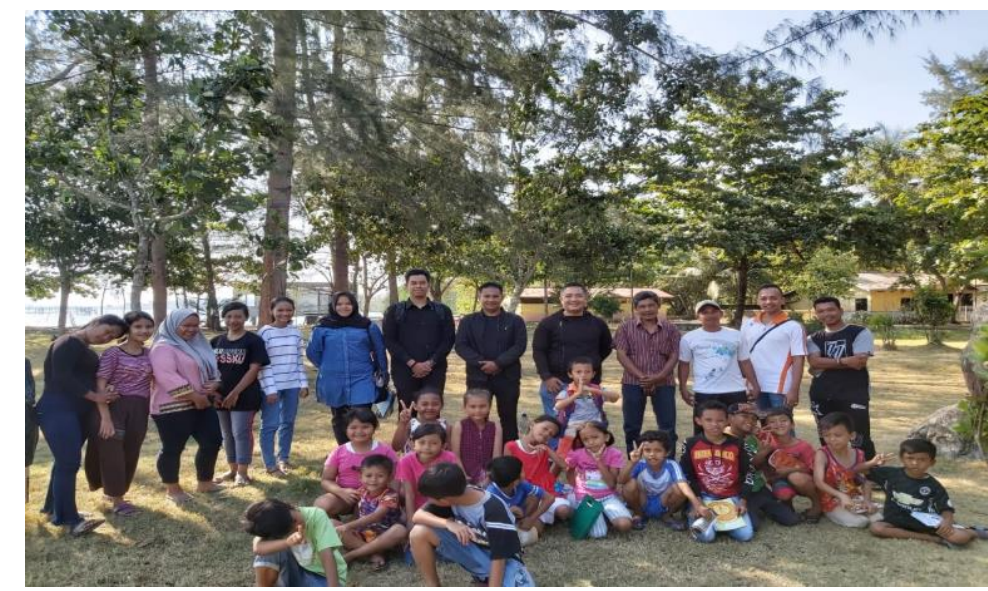

Gambar 4. Pelaksanaan PkM pada pertemuan terakhir pelaksanaan PkM di Taman Vihara Senggarang

\section{Kesimpulan}

Teknik Stepping the 5 Stairs "A" untuk belajar Grammar dalam kegiatan PkM ini tidak sebatas hanya diimplementasikan di lingkungan kelurahan Senggarang saja, tapi teknik ini dalam kegiatan PkM serupa juga bisa diimplementasi di lokasi atau daerah yang lainnya untuk jangka panjang. Kelebihan dalam pelasanaan PkM ini adalah sebagai berikut:

1. Adanya peningkatan pengetahuan dan pemahaman anak-anak pesisir tentang pembelajaran Grammar dengan menggunakan teknik Stepping the 5 Stairs "A";

2. Adanya motivasi anak-anak pesisir untuk tetap belajar Bahasa Inggris, khususnya Grammar;

3. Adanya keinginan para orang tua anak-anak pesisir juga untuk balajar Bahasa Inggris karena di tempat mereka merupakan tempat tujuan wisatawan asing; dan

4. Adanya permintaan dari anak-anak pesisir, para orang tua, RT, RW, dan Karang Taruna Senggarang kepada tim PkM untuk tetap meneruskan kegiatan serupa.

Ada pun kekurangan-kekurangan yang terdapat dalam pelaksanaan PkM tentang teknik stepping the 5 Stairs " $A$ " ini di antaranya adalah:

1. Waktu pelaksanaan PkM selalu berbenturan dengan libur nasional sehingga ada spaceatau jeda pertemuan;

2. Absensi salah satu tim PkM terkadang menghambat proses pembelajaran grammar dengan teknik stepping the 5 Stairs " $A$ ";

3. Keterbatasan peserta PkM yang akan terlibat karena harus disesuaikan dengan kemampuan dan keadaan anggaran PkM yang diterima;

4. Kegiatan PkM ini membutuhkan biaya yang lebih besar karena bukan sebatas kegiatan sosialisasi. Akan tetapi kegiatan reguler yang membutuhkan biaya lebih untuk operasional kegiatan.

\section{Saran}

Saran yang dapat diberikan pada pelaksanaan kegiatan PkM ini dengan mengingat besarnya manfaat dari program pengabdian ini maka selanjutnya perlu:

1. Mengadakan kegiatan serupa dengan melibatkan peserta yang lebih banyak; 
2. Menerapkan teknik pembelajaran grammar yang lainnya agar peserta PkM punya soft skill yang lainnya yang terdapat dalam teknik tersebut;

3. Peserta dapat mengimplementasikan teknik tersebut untuk mengkonstruksi kalminat-kalimat bahasa Inggris full verbs dengan benar dan akurat di sekolah mereka;

4. Besaran anggaran PkM yang pelaksanaannya reguler atau kontinu perlu dipertimbangkan lagi agar bisa ditambah.

\section{Ucapan Terimakasih}

Tim PkM mengucapkan terimakasih kepada LP3M UMRAH yang telah memfasilitasi dan memberikan support demi terlaksananya kegiatan PkM ini. Ucapan terimakasih berikutnya ditujukan kepada mahasiswa-mahasiswa Pendidikan Bahasa Inggris, Fakultas Keguruan dan Ilmu Pendidikan Universitas Maritim Raja Ali Haji yang telah terlibat superaktif dalam kegiatan ini, yakni Zethro Genik D., Diah Novrianty Utami, Sri Dwi Nurbayti, dan Elvinasafira.

\section{References}

Agust, S. (2017). Mastering the advanced grammar by stepping the 5 stairs up. Tanjungpinang: UMRAH PRESS.

Agust, S. (2019). Let's step the stairs to learn grammar. Tanjungpinang: UMRAH PRESS.

Al-Mekhlafi, A. M., \& Nagaratnam, R. P. (2011). Difficulties in teaching and learning grammar in an EFL context. International Journal of Instruction, 69-92.

Andy, R., \& Muzammil, L. (2018). Pelatihan berbahasa Inggris dengan drilling dan repetition bagi Karang Taruna Desa Jedong. MARTABE: Jurnal Pengabdian Masyarakat, 42-48.

Conrad, S. (2000). Will corpus linguistics revolutionize grammar teaching in the 21 st century? TESOL Quarterly, 548-559.

Ellis, N. C. (2005). How explicit knowledge affects implicit language learning. Studies in Second Language Learning, 305-352.

Ellis, R. (1995). Interpretation tasks for grammar teaching. TESOL Quarterly, 87-105.

Ellis, R. (2001). Investigating form-focused instruction. In R. Ellis (Ed.), Form-focused instruction and second language learning. Malden, MA: Blackwell.

Ellis, R. (2002). Does form-focused instruction affect the acquisition of implicit knowledge? A review of the research. Studies in Second Language Acquisition, 223-236.

Hahn, A. (2000). Grammar at its best: The development of a rule- and corpus-based grammar of English tenses. In L. Bernard \& T. McEnery (Eds.), Rethinking language pedagogy from a corpusbased perspective. Bern: Peter Lang.

Harley, B., \& Swain, M. (1984). The interlanguage of immersion students and its implications for second language teaching. Interlanguage, 291-311.

Hasanah, H. U. (2016). Respon mahasiswa terhadap pembelajaran grammar berbasis website. Nuansa, 5074.

Hinkel, E., \& Fotos, S. (2002). New perspectives on grammar teaching in second language classrooms. Mahwah, NJ: Erlbaum.

Hughes, R., \& McCarthy, M. (1998). From sentence to discourse: Discourse grammar and English language teaching. TESOL Quarterly, 263-287.

Lightbown, P. M. (1990). Focus-on-form and corrective feedback in communicative: Effects on second language learning. Studies in Second Language Acquisition, 429-448.

Lightbown, P. M. (2008). Transfer appropriate processing as a model for class second language acquisition. Understanding second language process, 27-44. 
Liu, D., \& Master, P. (2003). Grammar teaching in teacher education. Alexandria, VA: TESOL.

Navaz, A., \& Sama, F. (2017). Teaching grammar in the English language classroom: Perceptions and practices of students and teachers in the Ampara District. Proceedings of 7 th International Symposium, 653-667.

Philp, J. (2003). Constraints on "noticing the gap": Nonnative speakers' noticing of recasts in NS-NNS interaction. Studies in Second Language Acquisition, 99-126.

Ragan, T., Boyce, M., Redwine, D., Savenye, W., \& C., M. J. (1993). Is multimedia worth it? Association for Educational Communications and Technology Convention. New Orleans.

Risnawaty. (2018). Pelatihan Bahasa Inggris melalui media gambar dengan Direct Method (Metode Langsung). Prosiding Seminar Nasional Hasil Pengabdian, 323-327.

Setyowati, L., \& Muthoharoh, N. B. (2018). Penggunaan self-study book terhadap guru-guru Sakinah English Course. E-DIMAS: Jurnal Pengabdian kepada Masyarakat, 70-76.

Widyastuti, M., \& Kusumadewi, H. (2018). Penggunaan aplikasi Duolingo Dalam meningkatkan kamampuan kosakata Bahasa Inggris pada tenaga pengajar bimbingan belajar Omega Sains Institut. Jurnal Abdimas BSI, 237-244.

Yuan, F., \& Ellis, R. (2003). The effects of pre-task planning and on-line planning on fluency, and accuracy in L2 oral production. Applied Linguistics, 1-27. 